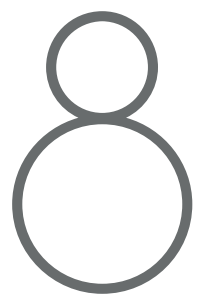

\title{
LOS SUEÑOS DE HERNÁN MALO
}

\author{
Carlos Paladines Escudero
}

I S Universidad Verdad, Núm. 1

Enero - Abril 1986, ISSN: 1390-28489 
En un acto académico celebrado en el aula magna de la Universidad Católica, en noviembre de 1977, con el objeto de analizar la marcha del Departamento de Filosofía, uno de los más queridos proyectos universitarios del entonces Rector de la Universidad, Dr. Hernán Malo González, se leyó el siguiente texto:

Es preciso soñar. Hay desacuerdo respecto al desacuerdo entre el sueño y la realidad. Mi sueño puede superar el curso natural ele los acontecimientos y puede también cambiar el rumbo ele una dirección que el curso ele los acontecimientos no podrá seguir nunca. En el primer caso, el sueño no es nada insano; incluso puede sostener y reforzar la energía del trabajador.... para emprender y llevar a término amplios y costosos trabajos en el campo de las artes, la ciencia y la vicia cotidiana... El desacuerdo entre el sueño y la realidad nada tiene de nocivo, siempre y cuando el hombre que sueña crea seriamente en su sueño, observe atentamente la vida, compare sus observaciones con sus castillos de naipes y, de una manera general, trabaje concienzudamente en la realización de su sueño (1).

Permítanme en esta ocasión bosquejar ante ustedes, tratar de revivir, algunos de los sueños de Hernán Malo González, sueños -varios de ellos- que lograron hacerse realidad, sueños -otros- que esperan aún de la fuerza de la razón y del tiempo para volverse historia.

Decía un autor, que recoger esos sueños e ideas de manos de un hombre venerable, sostenerlos con el vigor de la juventud, hacer- los crecer con la fuerza de la razón, pasarlos a otras manos más nuevas y a otros espíritus más clarividentes, es ya en sí un homenaje, seguramente el homenaje que hubiera llenado de satisfacción a quien hizo que el eje de su pensamiento de madurez sea la lucha por una gran tesis: La Universidad sede de la razón (2).

\section{Sueño Primero}

Inició Malo su lucha por convertir a la universidad en sede de la razón, trabajando por su democratización. En un ambiente propicio de verticalismo en la toma de decisiones y al ejercicio y control del poder a través de pocas manos, Hernán Malo batalló concienzudamente por hacer realidad en la vida universitaria la gestión, los hábitos, las reglas del juego democrático. Es paradójico que en uno de los más largos períodos del gobierno militar que ha conocido el país, se comenzara en la Universidad 
Católica a escoger algunas de sus autoridades mediante la libre elección de profesores y estudiantes, a conformar el Consejo Académico con la participación y representatividad del conjunto de los estamentos universitarios, a constituirse asociaciones de profesores y trabajadores, y llegó el Rector incluso a defender a Obispos y a políticos que la dictadura militar confinó en varias ocasiones en las cárceles.

Fue alentador en esos tiempos hablar en la Universidad de democracia, participación, cogobierno, comunidad universitaria; lo difícil fue sostener esos sueños. Los guardianes del antiguo orden terminaron por reimplantar superadas formas de gobierno, tras una larga campaña en que la vorágine de la manipulación política hizo perder el norte de la razón a la sede misma de la razón.

Pero democratizar una Universidad no era sólo un problema de organización de su administración o su poder; junto a esa tarea, Hernán Malo González buscó robustecer una política de pluralismo ideológico, libertad de cátedra y apertura de una crítica fundamentada y sólo limitada por la racionalidad; todo esto con miras a crear el ambiente que hoy requiere la ciencia, la investigación y la excelencia académica para no languidecer. Sin participación efectiva en la toma de decisiones universitarias, el diálogo en la vida académica termina por transformarse en un monólogo.

\section{Segundo Sueño}

La Universidad, sede de la razón, también supuso para Hernán Malo González trabajar concienzudamente por ecuatorianizarla.

Fue y es paradójico que una Universidad ecuatoriana requiera ser ecuatorianizada, pero la razón crítica y la autocrítica universitaria testimoniaban que ella había dado sus espaldas a la realidad que la circundaba, a los retos y urgentes demandas de su medio.

A quienes sintieron en carne propia la necesidad de no permanecer ni un día más de espaldas a la realidad y se esforzaron por cambiar dicho rumbo, les es fácil reconocer lo penoso que fue pasar a programas y hechos concretos a fin de ecuatorianizar la Universidad; el ambiente universitario era propició para "buenas intenciones" o "declaraciones de principios", mas para romper dependencias culturales centenarias que en muchos casos estaban ahincadas más dentro que fuera de nosotros mismos y que se resistían a reconocer nuevos derroteros en el quehacer universitario. 
Malo se esforzó por constituir centros de investigación nacional, por revisar los programas de estudio vigentes, por fundar una Facultad de Ciencias Humanas con especial dedicación al estudio del pensamiento, la antropología y la política ecuatoriana, por implementar una oficina de planificación académica, por rescatar nuestro acervo cultural: Museo Jacinto Jijón y Caamaño, Biblioteca Aurelio Espinosa Pólit, Corporación Editora Nacional. Condujo así Malo adelante uno de los mayores programas de ecuatorianización de la Universidad que ha conocido el Ecuador contemporáneo y él mismo en sus clases dio testimonio no sólo de excelencia académica, sino también de dedicación a la investigación de nuestro pensamiento y de nuestras instituciones.

Pero sería traicionar al proceso de ecuatorianización de la Universidad el concebirlo en su fase tan sólo académica. A la excelencia académica unió Malo el servicio de la razón, que en su último vértice apuntaba a la causa de los pobres, a la denuncia de la violencia y explotación que sufre nuestro pueblo. Malo soñó en una Universidad inquieta y preocupada por las necesidades y problemas de los grupos sociales menos favorecidos y puesta por ende a su servicio, a través de una razón práctica y operante y aun de una razón política que impusiese sobre el simplismo, la generalización y la demagogia en la explicación de los problemas, la precisión, la programación, el análisis y la lógica. Su contribución al establecimiento de la pensión diferenciada, el surgimiento de la extensión universitaria, la promoción social, los servicios jurídicos, médicos y dentales gratuitos, la creación del Departamento de Bienestar Estudiantil, testimonian su contribución al establecimiento de una orientación social en la Universidad.

\section{Sueño Tercero}

Transformar a la Universidad en sede la razón supuso también para Hernán Malo el promover un diálogo civilizado con las otras universidades del país. A él le tocó romper un inveterado enclaustramiento y en dicha marcha arrastra tras de sí también a las otras Universidades Católicas del país.

Pero sería también injusto reducir su propuesta a un mero sentarse en la misma mesa de negociaciones. Malo soñó en empresas académicas mutuas, en investigaciones inter universitarias, en una planificación de los recursos humanos, técnicos y financieros del conjunto de las Universidades; y, especialmente en terminar con los privilegios que separaban a las universidades, proponiendo una estructura básica que no establecía sino una organización mínima general, dejando las especificidades propias de $\cdot$ cada Universidad para que sean concretadas autónomamente por cada una de ellas. 


\section{Cuarto Sueño}

La Universidad Sede de la Razón, en otros términos: que en la Universidad prime la razón.

Hernán Malo en su obra Pensamiento Universitario Ecuatoriano, señala las condiciones y requisitos que habían de cumplirse para que una Universidad sea de verdad la sede, el lugar de la razón. En otros términos, Malo tuvo el acierto de esclarecer un concepto tan equívoco y enfermo de polisemia como es el de la razón (3).

Sucintamente, para Hernán Malo una Universidad era tal en la medida en que respetase la autonomía de la razón, se comprometiese a través de la razón en la búsqueda constante de la verdad, desplegarse sin temor la dimensión crítica de la razón, su dimensión dialéctica o dialogante, así como también su dimensión práctica y por supuesto también política.

No es apropiado tratar de penetrar este momento en el alcance de estos sueños o lineamientos, pero al menos permítanme resaltar uno de ellos.

Malo González, sin ser Kantiano, reconocía la función activa y hasta creadora del pensamiento humano; igualmente, sin ser empirista, reconocía que la naturaleza brindaba todo su sentido, pero sólo en la medida de su relación con la existencia humana. En esta forma enzarzaba la razón teórica con la razón práctica. En palabras de él: La razón práctica debe funcionar en íntima relación con la instancia suprema de la razón teórica, la cual reside autónomamente en la Universidad. Y no cabe duda que cuando en la Universidad se haya realizado esta síntesis habremos superado una razón y el despliegue de la misma a través de razonamiento y de discursos en los cuales se encierra tan sólo una razón abstracta, llena de "buenas intenciones" y "declaraciones de principios" o una razón concreta, incapaz de ver más allá de sus propios intereses.

\section{Quinto y Último Sueño.}

Construir una Universidad como Sede de la Razón, le tocó a Hernán Malo ejecutarlo en el marco de la Universidad Católica y esta especificidad consideró él que no emanaba ni de la estructura de su organización ni del carácter religioso o no de sus integrantes, sino de aspectos que revisten mayor- importancia como es el de promover a través de la Facultad de Teología, Facultad que fue adscrita a la Universidad durante su rectorado, el diálogo con otras disciplinas de tal 
modo que se exprese el punto de vista teológico sobre los problemas suscitados por las coyunturas científicas, sociales, locales y nacionales, como afirman los lineamientos generales de su plan maestro.

Por supuesto sus sueños fueron más allá de los aquí descritos; por ejemplo, no se ha tratado la cara humanística de la Universidad que debía complementarse de modo armonioso con los aspectos científicos y técnicos, integración creativa de estas funciones y que avizoró ya uno de sus antepasados, Benigno Malo, y que tan bellamente describe Hernán al estudiar las dos ocasiones de la Universidad ecuatoriana del siglo XIX: la de García Moreno y la de Benigno Malo (4).

No me he atrevido hoy a tocar los sueños de Malo ubicados más allá del campus universitario, que sin lugar a dudas constituyen otra parte muy significativa de su herencia cultural; juzgo que los sueños descritos esta noche son suficientes para aquilatar su personalidad y afirmar como lo hizo José Valencia, en homenaje similar a éste, que la Universidad Católica quedó signada por el paso de Hernán Malo González en un antes de Hernán Malo González y en un después de Hernán Malo González (5), que con sus sombras y sus sueños abarcó y alumbró una etapa importante no sólo de la historia de la Universidad Católica, o de la "generación" que debe a Hernán, a su labor de compañero y maestro, su identidad intelectual y la orientación robusta de su compromiso revolucionario (6), sino también de la misma universidad ecuatoriana en general.

\section{NOTAS}

(1) Cfr. Carlos Paladines. Informe del Director Encargado del Dpto. de Filosofía, de la PUCE, X-75 - X-77, págs. 10-1 l. Nov. 16 de 1977.

(2) Cfr. Simón Espinosa. In memoriam de Hernán Malo González, Aula Magna, PUCE. 6 de octubre de 1983.

(3) Confr. Hernán Malo Gollzález. Pensamiento Universitario Ecuatoriano, págs. 45-5J: Corporación Editora Nacional, V. 14. Quilo, 1951.

(4) Conf. Idem., págs. 58, 55.

(5) Confr. Enrique Ayala Mora. Homenaje Póstumo a Hernán Malo González, Cuenca, 6 de septiembre de 1983. 
